\title{
Gelir Eşitsizliği ve Ekonomik Büyüme İlişkisi: Geçiş Ekonomileri Üzerine Panel Veri Analizi ${ }^{1}$
}

Gelir Eşitsizliği ve Ekonomik Büyüme İlişkisi: Geçiş Ekonomileri Üzerine Panel Veri Analizi

\section{Öz}

Üretim süreçleri sonucunda yaratılan değeri ifade eden gelirin, bireyler arasındaki dağılımı bakımından ülke ekonomilerini önemli ölçüde etkilediği iler sürülmektedir. Gelir dağııımını etkileyen çok sayıda ve çeşit te unsur bulunmaktadır. Bu çalışma da ekonomik büyümenin gelir dağılımının üzerindeki etkileri geçiş ekonomisine sahip seçilen on ülke için 1995-2013 yıllarına ait ekonomik büyüme ve Gini değerleri kullanılarak statik panel veri yöntemi ile analiz edilmiştir. Çalışmanın temel amacı Kuznets ters- $U$ hipotezinin geçiş ekonomileri için geçerliliğini test etmektir. Yapılan çalışmanın bulgularına göre, geçiş ekonomisine sahip ülkelerde Kuznets'in ters-U hipotezine uygun olarak ekonomik gelişmenin ilk aşamalarında gelir eşitsizliğinin arttığı tespit edilmiştir. Gelişmenin sonraki aşamalarında ise ekonomik büyümenin gelir eşitsizliğini azaltıcı bir etkiye sahip olduğu tespit edilmiştir. Kontrol değişkenlerinden eğitime katılım oranının istatiksel olarak anlamlı olduğu görülmüştür. Kamu harcamalarının gelir eşitsizliği üzerinde etkisi istatistiki olarak anlamlı bir sonuç vermemiştir. Elde edilen sonuçlar, incelenen geçiş ekonomilerine sahip ülkelerde Kuznets'in ters-U hipotezini desteklemektedir.

Anahtar Kelimeler: Ekonomik Büyüme, Geçiş Ekonomileri, Gelir Eşitsizliği, Statik Panel Veri Analizi.
The Relationships between Income Inequality and Economic Growth: Panel Data Analysis on Transition Economies

Abstract

It is argued that income, which represents the value created as a result of the production processes, has a significant impact on the economies of the country in terms of the income distribution. There are many and varied factors affecting income distribution. In this study, the effects of economic growth on income distribution were analyzed by using static panel data method. Economic growth and Gini data for the years 1995-2013 were used for ten selected transition economies. The main purpose of the study is to test the validity of the Kuznets inverse- $U$ hypothesis for transition economies. According to the findings of the study, income inequality increased in the early stages of economic development in transition economies, consistent with the Kuznets inverse- $U$ hypothesis. In the later stages of the development, it was found that economic growth had a decreasing effect on income inequality. Among the control variables, education was found to be statistically significant. The effect of public expenditures on income inequality was not statistically significant. Overall, the results support the Kuznets inverse-U hypothesis in transition economies examined.

Keywords: Economic Growth, Transition Economies, Income Inequality, Static Panel Data Analysis.

\section{Giriş}

Ekonomik faaliyetler bireyler, firmalar, kurumlar ve ülkeler için bir takım amaçlar veya hedefler doğrultusunda gerçekleşmektedir. Herhangi bir toplumdaki bireyin temel amacı ekonomik yaşam içerisinde kendisine maksimum faydayı sağlamak iken firmaların temel hedefi ise kâr maksimizasyonu olmaktadır. Devletlerin temel amacı da ekonomik yaşamın aksaklık olmadan devam etmesini sağlamaktır. Bireylerin ve firmaların maksimizasyoncu davranışları her alanda ya da tüm piyasalar için geçerli olacaktır. Ekonomik gelişmenin tarihsel olarak başlangıç dönemlerinde ülke ekonomilerine yön veren kamu otoritesinin düzenleme görevi oldukça basit olarak görülmektedir. Ancak zamanla küreselleşme, hızla ilerleyen teknoloji gibi faktörlerin etkisi ile

\footnotetext{
${ }^{1}$ Bu çalışma 18-20 Mayıs 2017 tarihinde 2. Uluslararası Sosyal Bilimler Sempozyumu'nda sunulan özet bildirinin geliştirilmiş halidir.

2 Dr.Öğr.Üyesi, Eskişehir Osmangazi Üniversitesi iiBF, İktisat Bölümü, msengur@ogu.edu.tr, Yazar ORCID bilgisi: https://orcid.org/0000-0002-2173-9977
} 
çok hızlı gelişim ve değişim gösteren ekonomik yaşam günümüzde oldukça karmaşık bir hal almıştır. Her ekonomi için basit şekilde ne üretilecek, nasıl üretilecek ve kimler için üretilecek temelinde yapılan sorgulara ek olarak yeni ve sayısı oldukça fazla olan sorular ortaya çıkmıştır.

Ortaya çıkan sorunların en başında ise bölüşüm gelmektedir. Çünkü dünya üzerinde üretimin hiç olmadığı kadar arttığı ve ileri teknolojilerin kullanıldığı günümüzde gelirin ise hiç olmadığı kadar eşitsiz paylaşıldığı görülmektedir. Gelirin meydana getirilmesi ne kadar önemli ise elde edilen hâsılanın paylaşımı da ekonomik devamlılık ve sürdürülebilirlik açısından son derece önemlidir. Eğer toplumdaki tüm bireylerden gelirden aynı oranda pay alırsa dağılımında eşitlik sağlanmış olur. Ancak bu eşit dağılım sağlanamaz ise gelir eşitsizliği ile yüzleşmek kaçınılmaz olacaktır.

Çalışmanın temel amacı Kuznets'in ters-U hipotezinin geçiş ekonomileri olarak adlandırılan ülkeler için geçerliliğini sorgulamaktadır. Çalışmada analiz geçiş ekonomileri içerisinde yer alan on ülke ve 1995-2013 yılları arasındaki zaman dilimi ile sınırlandırılmıştır. Bunun temel nedeni tüm geçiş ülkelerini verilerinin gerek ülke gerekse yıl bazında elde edilemeyişidir. Çalışmanın hareket noktası yani temel varsayımı Kuznets hipotezinin geçiş ekonomilerinde de geçerli olmasıdır.

Çalışmada gelir dağılımı eşitliği ile ekonomik büyüme arasındaki ilişki geçiş ekonomileri için incelenmiştir. Bu ilişki incelenirken başlangıçta araştırılan problem teorik olarak temellendirilmiş ve sonrasında literatürdeki başlıca benzer çalışmalar özetlenmiştir. Teorik çerçeveden sonra geçiş ekonomileri olarak adlandırılan ülke örnekleri için ekonomik büyüme gelir eşitsizliği ilişkisi Kuznet's Ters-U Hipotezi'ne göre panel veri analizi yöntemi ile araştırılmıştır.

\section{Literatür}

Literatürde Kuznets'in ortaya koyduğu gelir eşitsizliği ve ekonomik büyüme ilişkisini test eden sayısız çalışma bulunmaktadır. Bu çalışmaların büyük bir kısmında Kuznets hipotezi doğrulanırken geriye kalan bölümünde ise hipotez reddedilmiştir. Günümüzde yapılan çalışmalarda da üzerinde anlaşılan tek bir netice bulunmamakla birlikte her geçen gün Kuznets hipotezi üzerine yeni araştırmalar ortaya konulmaktadır.

Paukert, gelir eşitsizliği ile ekonomik gelişmişlik arasındaki ilişkiyi 56 ülkeyi dikkate alarak araştırmıştır. Gelir eşitsizliğini etkileri bakımından ülkeler için ayrıştırdığında gelişmiş ülkeler bakımından gelirin daha eşitsiz dağıldığını tespit etmiştir. Ekonomik bakımından daha gelişmiş ülkelerde gelir eşitsizliğinin diğer ülkelere göre daha fazla olması, Kuznets'in hipotezinde ortaya koyduğu gelişmenin ilk aşamasında eşitsizliğin artacağı öngörüsünü destekleyici bir sonuçtur (Paukert, 1973). Paukert'in çalışması bir bakıma gelişmiş ve gelişmekte olan ülkeler bakımından Kuznets hipotezinin farklılaştığı görülmektedir. Gelişmekte olan ya da gelişmemiş ülkelerin ilgili dönemde ekonomik gelişim sürecinde de geride olmaları sebebiyle bu sonuç ortaya çıkmaktadır.

Ekonomik yapının iki sektörden oluştuğu varsayımı ile hareket edilmesi çoğu zaman tercih edilen bir yöntemdir. Bu yöntemin tercih edilmesinin temel sebebi basitleştirme ile ekonomik işleyesi daha net ortaya koyma çabasıdır. Robinson (1976), dözünü ettiğimiz ve birçok ekonomist tarafından kullanılan iki sektörlü bir ekonomi modeli ile Kuznets hipotezinin geçerliliğini incelemiştir. Sektörlerin nüfus payları değiştikçe uzun dönemde gelir eşitsizliği artmaktadır. Ayrıca bu sonuç Adelman ve Morris'in (1973) ampirik bulguları ile de tutarlıdır.

Ram, dünya nüfusunun yaklaşık \%85'ni temsil eden 115 piyasa ekonomisi ülkesini 19601980 dönemi için Theil endeksini kullanarak analiz etmiştir. Belirtilen dönem için yapılan analiz 
sonucu Kuznets'in hipotezini ve bu konuda yapılan çalışmaları destekler niteliktedir (Ram 1989). Ram'ın yaptığı çalışmanın en önemli özelliği dünya genelini yansıtmasıdır. Çünkü yapılan çalışmaların çoğu ya belirli bir ülke ya da belirli bir ülke grubunu analiz etmektedir.

Yapılan ampirik bir çok çalışma ekonomik büyüme ile gelir eşitsizliği arasındaki ilişkinin Kuznets hipotezini destekler olduğu ortaya koymuşken Anand ve Kanbur tam olarak geçerli olmadığını tespit etmişlerdir. Anand ve Kanbur (1993a, 1993b), gelir eşitsizliği ile ekonomik büyüme arasındaki ilişkiyi Kuznets'in sosyal, politik ve ekonomik bir takım araçlarla açıklamaya çalıştığını ve bu konudaki tahminlerini ülkelerin gelişme serüvenlerindeki davranışlardan türettiğini belirtmişlerdir. Daha sonra ise 1953-1976 dönemini için gelişmiş ve gelişmekte olan 60 ülkeyi ele alarak Kuznets'in hipotezini test etmişlerdir. Yapılan yatay kesit analizi sonucunda Kuznets hipotezinin ortaya koyduğu varsayımların geçerli olmadığı saptanmıştır.

Clarke, yaptığı regresyon analizlerinin sonucunda büyümenin istenmeyen sonucu olduğu varsayılan gelir eşitsizliği ile ilişkisinin sanılanın aksine negatif yönlü olduğunu tespit etmiştir. Ekonomik büyüme ile gelir eşitsizliği arasında istatistiki olarak anlamlı olan negatif yönlü bir ilişki saptamıştır. Ayrıca Clarke göre, bu ilişki demokratik olan ve olmayan ülkelerde benzer şekilde görülmekte olup aksine ilişkinin boyutu sanılanın oldukça küçüktür (Clarke 1995). Anand ve Kanbur'un elde ettiği sonuçlar ile benzerlik gösteren bu uygulamanın temel farkı demokratik olan ve olmayan ülkeler için herhangi bir farklılı̆ı̆n olmayışıdır.

Ram(1997), neredeyse dönemin tüm gelişmiş ülkelerini kapsayacak bir veri seti ile 19 ülke için panel veri analizi yapılmıştır. Sonuçta ABD (Amerika Birleşik Devleti) için ortaya konulan modele uygun olarak ters-U hipotezinin diğer ülkeler için de geçerli olduğu tespit edilmiştir. Gelirin 1950 ile 1960 yılları arasında tipik olarak azaldığı ancak 1970'ler süresince de arttığı gözlenmiştir. Dawson (1997), az gelişmiş 36 ülke için Kuznets hipotezini iki farklı model ile test etmiştir. İlk model orijinal Kuznets fonksiyonu üzerine kurulmuş ve ikinci model ise yarı logaritmik fonksiyon kullanılarak oluşturulmuştur. Kurulan modellerin sonuçlarına göre 1980 yılı fiyatları ile 39 ülke için gelir eşitsizliğinin önce arttığı, zirveye ulaştıktan sonra da azaldığı tespit edilmiştir. Dolayısıyla ters-U hipotezi ile uyumlu bir sonuca ulaşılmıştır. Ram ve Dawson tarafından yapılan her iki çalışma da Kuznets'in ters-U hipotezini desteklemektedir. İki çalışmayı birbirinden ayrıt eden ise birsi gelişmiş ülkeleri incelerken diğerinin ise az gelişmiş ülke gruplarını ele almış olmasıdır. Ayrıca bu sonuçlar Paukert (1973) tarafında elde edilen bulgulara göre farklılık göstermektedir. Paukert gelişmiş ülkeler için Kuznets hipotezini doğrularken gelişmemiş ülkeler için geçerli olmadığını tespit etmiştir.

Ram ve Dawson'ın bağımsız olarak yaptıkları çalışmalarda kullandıkları gelişmiş ve az gelişmiş ülkeleri tek bir çalışmada ele alan diğer bir analiz ise Matyas vd., tarafından yapılmıştır. Matyas vd., (1998), gelişmiş ve gelişmekte olan ülkeler için 1970-1993 dönemi verilerini kullanarak panel veri analizi yapmışlardır. Kuznets hipotezinin test edilmesinde orijinal ikinci derece fonksiyonun yanı sıra üçüncü derece fonksiyonu da kullanılmıştır. Ancak her durumda Kuznets hipotezini doğrulayıcı bir sonuca ulaşılamamıştır. Zang (1998), yatay kesit ve zaman serisi analizi ile 60 ülkenin 1967-1986 yılları içinde Kuznets hipotezinin geçerliliğini sorgulanmıştır. Analiz sonuçlarında ilgili dönemde Kuznets eğrisinin istikrarlı bir seyir izlediği ve hipotezin geçerli olduğu tespit edilmiştir.

List ve Gallet, çalışmada Kuznets hipotezi çerçevesinde 71 ülke için 1961-1992 dönemi verilerini kullanılarak ekonomik büyüme gelir eşitsizliği ilişkisi test edilmiştir. Yapılan panel veri analizi sonuçları Kuznets hipotezini desteklemektedir. Daha az gelişmişülkeler için ilişki ters-U şeklinde iken gelişmişlik düzeyi yüksek ülkeler için belirli bir noktadan sonra ilişki yeniden pozitif 
olmaktadır (List ve Gallet (1999). List ve Gallet'in elde ettiği sonuçlar literatürde yer alan diğer çalışmalar ile örtüşmektedir. Kuznets hipotezinin geçerliliğini yanı sıra gelişmiş ve az gelişmiş ülkeler için elde edilen bulguların farklııık gösterdiği görülmektedir. Paukert (1973), tarafından yapılan çalışmanın bulguları ile benzer sonuçların ortaya çıktığı görülmektedir.

Barro (2000), gelir eşitsizliği ve ekonomik büyüme ilişkisini panel veri analizi ile incelemiştir. Analiz sonuçları genel olarak Kuznets hipotezi ile uyumludur. Yüksek gelir eşitsizliğinin yoksul ülkelerde ekonomik büyümeyi geciktirirken zengin ülkelerde hızlandırdı̆̆ı tespit edilmiştir. Bu ilişki ülkeler arasındaki eşitsizlik farklılıklarını ve zaman içindeki değişimi açıklayamamaktadır. Thornton (2001), savaş sonrası döneme ait gelir miktarları ve kişi başı reel gelirlerini dikkate alarak 96 ülkeyi panel veri analizi ile incelemiştir. Bağımlı değişken olarak Gini katsayısının kullanıldığı analiz sonuçlarına göre ekonomik gelişme ile gelir eşitsizliği arasındaki ilişkinin Kuznets'in ters-U hipotezinde varsayımlarla örtüştüğü tespit edilmiştir. Barro ve Thornton tarafından yapılan panel veri analizinin kullanıldığı çalışmaların ters-U hipotezini desteklediği görülmektedir. Ancak Barro (2000) tarafından yapılan çalışmada yoksul ülkelerdeki eşitsizliğin büyümeyi geciktirici etkisinin olduğu da vurgulanmaktadır.

Kuznets hipotezini destekleyen ya da desteklemeyen çalışmalardaki ilişkinin bir şekilde güçlü olduğu ortaya konulmuştur. Ancak gelir eşitsizliği ile ekonomik büyüme arasındaki ilişkinin sanıldığı kadar güçlü olmadığı ifade eden çalışmalar da bulunmaktadır. Nel (2003), 1986-1987 yıllarına ait hanehalkı harcama verilerini kullanarak Afrika ülkeleri için regresyon analizi yapmıştır. Çalışma sonucunda yüksek gelir eşitsizliğinin orta vadede ekonomik büyüme üzerindeki etkisinin negatif olduğu tespit edilmiştir. Diğer bir tespit ise, gelir eşitsizliği ekonomik büyüme arasındaki ilişkinin çok güçlü olmadığıdır.

Chen (2003), ikinci dünya savaşı sonrası, yüksek gelir eşitsizliği karşısında düşük ekonomik büyüme sergileyen ya da düşük gelir eşitsizliği karşısında yüksek büyüme ortaya koyan ülkelerin varlığından yola çıkarak ülke grupları için panel veri analizi yapmıştır. Analiz sonucunda gelir eşitsizliğinin gelir seviyesine göre önce arttığı sonra ise azaldığı görülmüştür. Bu sonuç, Kuznets'in ters-U hipotezi ile benzemektedir. Ancak diğer bir sonuç olan uzun vadeli gelir artış oranı ilk önce artar ve sonra ilk gelir eşitsizliği ile birlikte düşmesi durumu ters-U hipotezine göre farklılığını ortaya koymaktadır. Huang (2004), geleneksel yaklaşımların aksine doğrusal olmayan esnek bir yöntem ile Gini katsayısı kullanılarak gelir eşitsizliği ekonomik büyüme ilişkisi araştırılmıştır. Doğrusal olmayan bu yaklaşımın ilişkinin tam olarak açıklanmasında daha faydalı olacağı savunulmuştur. Doğrusal olmayan bu model ile analiz edilen 75 ülke için sonuçlar diğer geleneksel model sonuçları ile benzerlik göstermiştir. Kişi başı gelir ile eşitsizlik arasındaki ilişki ters$\mathrm{U}$ şeklinde hareket etmektedir.

Ülkelerin gelişmiş ya da az gelişmiş olarak net bir şekilde ayrıldığı yapılan analizlerde görülmektedir. Ancak gelişme serüvenine henüz yeni başlamış ya da gelişme serüveni sonuçlanmamış ülkelerin de olduğu diğer bir gerçektir. Ülke sınıflandırmasını bu doğrultuda yapan ampirik çalışmalarda bulunmaktadır. Ongan (2004), gelişmiş ve gelişme sürecini henüz tamamlamamış ülkeler için gelir eşitsizliği doğrudan yabancı sermaye yatırımları arasındaki ilişki araştırmıştır. Çalışmanın bir sonucu da ekonomik büyüme ile gelir eşitsizliği arasında ters-U şeklinde bir ilişki olmasıdır. Kalkınma sürecinin ortalarında olan ülkeler için gelir eşitsizliğinin diğer ülkelere göre daha fazla olduğu da görülmüştür. Khasru ve Jalil (2004), gelişmiş ve gelişme sürecinde olan ülkeler için ters-U hipotezinin geçerliliğini araştırmışlardır. Gelir eşitsizliği ile ekonomik büyüme arasındaki ilişkisinin aslında Kuznests'in ortaya koyduğundan çok daha karmaşık olduğunu be- 
lirtmişlerdir. Zaman serisi ve panel veri analizi olarak yapılan araştırmada 37 yıllık veri seti kullanılmış olup ülkelerin gelişmiş düzeyine göre ters-U hipotezinin geçerliliği farklıdır. Gelişmekte olan ülkelerde ters-U hipotezi geçerli iken gelişmiş ülkeler için İrlanda, Hindistan ve İngiltere dışındaki ülkeler için geçerli değildir.

Deutsch ve Silber (2004), fonksiyonel ve kişisel gelir dağılımı ile ekonomik gelişme arasındaki ilişkide Kuznets hipotezinin geçerliliğini incelmişlerdir. Kuznets eğrisinin ilk aşamasında yaşanan gelir eşitsizliğinin mülk ve servet gelirinin etkisine rağmen Kuznets'in de ifade ettiği gibi ücretlerden kaynaklandığı tespit edilmiştir. Eğrinin ikinci kısmı artan mülkiyet veya kaynak geliri eşitsizliğinin, girişimcinin azalan gelirinin ve transferlerin bir sonucu olduğu görülmüştür. Gallet ve Gallet (2004), ABD için 1947-1998 dönemi verileri kullanılarak aşamalı regresyon yöntemi ile Kuznets hipotezi sınamıştır. ABD nüfusunun farklı bölümleri (siyah ve beyazlar) için yapılan analiz sonuçlarına göre Kuznets eğrisi ters $-U$ şeklinde olmayıp sadece $U$ şeklindedir. Özellikle 1950'li yıllardaki yapısal kırılmalar ile bu durum daha belirgin olarak tespit edilmiştir.

Kuştepeli (2006), AB (Avrupa Birliği) üyesi ve AB üyesi olmaya aday ülkelerin 1951-1998 yılları arasındaki verilerini kullanarak Kuznets hipotezinin geçerliliğini test etmiştir. İkinci dereceden fonksiyonun kullanıldığı modelde Kuznets hipotezini doğrulayan sonuçlara ulaşmışlardır. Kuştepeli tarafından yapılan çalışma AB standartlarında ya da o standartlara yakınsama çabasında olan ülkeler için ters-U hipotezinin geçerliliğini ortaya koymaktadır. Dolayısıyla Afrika, Asya ya da Amerika kıtasındaki ülkeler ile benzer bir sonuç elde edilmiştir.

Tokatlıoğlu ve Atan (2007), 2003 yılı verileriyle yatay kesit analizi ile ters-U hipotezinin geçerliliği Türkiye için araştırılmıştır. Türkiye'de her bölgedeki farklı istihdam yapısının farklı eşitsizlik düzeylerine sebep olmasından dolayı zaman serisi verisi temin edilememiştir. Analiz sonucunda üçüncü dereceden bir fonksiyon yardımı ile yapılan analiz sonucunda Türkiye'de ters$U$ hipotezinin sadece $U$ şeklinde olduğu tespit edilmiştir. Dişbudak ve Süslü (2007), Türkiye'de 1963-1998 dönemi için bireysel gelir dağılımın makroekonomik belirleyicilerini ARDL analizi ile araştırmışlardır. Analiz sonucunda iktisadi büyümenin kısa dönemde gelir dağılımı üzerinde negatif bir etkisi varken uzun dönemde bu etki pozitife dönmektedir.

Derviş (2007), dünya genelinde gerçekleşen hızlı büyümeden gelişmekte olan ülkeler de pozitif etkilenmişlerdir. Ancak bazı gelişmekte olan ülkeler bu büyüme trendini yakalayamamışlar ve uzaksama eğilimi göstermişlerdir. Sadece uzaksama eğilim gösteren ülkeler değil hızlı büyüme performansı ortaya koyan ülkeler için bile gelir adil bir şekilde dağılım göstermemiştir. Rehme (2007), eğitim, ekonomik büyüme ve gelir eşitsizliği ilişkisini Lorenz baskınlık kriterine ve Gini katsayısına göre incelemiştir. Büyüme ve gelir eşitsizliği arasında fonksiyonel olmayan bir ilişkinin var olduğu tespit edilen çalışmada eğitimin hem ekonomik büyüme hem de gelir eşitsizliği üzerinde etkili olduğu tespit edilmiştir.

Rehman vd. (2008), ekonomik büyümenin farklı aşamalarındaki 51 tane farklı ülkeye ait 1975-2002 dönemi verileri ile gelir eşitsizliğini etkileyen faktörlerin tespiti panel veri analizi yöntemi uygulamışlardır. Bu ülke grupları; düşük gelirli, düşük orta gelirli, üst gelirli ve en yüksek gelire sahip ülkeler olarak sınıflandırılmıştır. Yapılan çalışmanın sonucunda ters-U hipotezi desteklenmektedir. Ancak finansal gelişmenin, gelişme aşamalarına bağı kalmaksızın eşitsizliği azaltmasından dolayı gelir eşitsizliği ile ilişkisinde ters-U hipotezinin geçerliliği için yeterli kanıtın olmadığını belirtmişlerdir.

Shahbaz (2010), Pakistan için 1971-2005 dönemi verileri ile gelir eşitsizliği ve ekonomik büyüme ilişkisini Kuznets tesr-U hipotezi çerçevesinde araştırmıştır. Yapılan zaman serisi analizi 
sonuçlarına göre ters-U hipotezi ilişkisinin geçerli olduğu ancak Pakistan için ters-S eğrisi şeklinde olduğu saptanmıştır. Mollick (2011), ABD için 1912-2002 dönemi verileri ile panel veri analizi yöntemi ile Kuznets hipotezi test edilmiştir. Analiz sonucunda Kuznets hipotezini destekleyici sonuçlar elde edilmiştir. Muinelo ve Roca (2011), üst orta ve yüksek gelirli ülkeler için yaptıkları araştırmada artan vergilerin ve harcamaların gelir dağılımı üzerinde eşitlikçi bir etkisi varken büyüme üzerinde negatif bir etkisi olduğu tespit edilmiştir.

Kuznets'in ters-U hipotezinin tamamen geçerli olmadığı ortaya koyan farkı ülkeler için farklı dönemleri kapsayan çalışmalarda mevcuttur. Bu çalışmalar ters-U hipotezini tamamen reddetmemekle birlikte tamamıyla doğrulamamaktadırlar. Elde edilen bulgular daha çok ortaya konulan ilişkinin kısmen veya tek yönlü geçerli olduğu yönündedir. Desbordes ve Verardi (2012), 113 ülke için 1960-2000 yıllarını kapsayan panel veri analizi ile ekonomik gelişme ile gelir eşitsizliği ilişkisi incelenmiştir. Ekonomik gelişme ile gelir eşitsizliği arasında ters-U şeklinde bir ilişkinin olduğu ancak bunun nedensel bir ilişki olmadığı tespit edilmiştir. Ekonomik gelişmenin tek başına daha adil bir gelir dağılımına yol açma eğilimi olduğu görülmüştür. Malinen (2012), gelir eşitsizliği ile ekonomik büyüme arasında uzun dönemli istikrarlı bir denge ilişkisi olup olmadığını 38 Latin Amerika ülkesi için araştırmıştır. Analiz sonuçlarına göre, uzun dönemli ekonomik büyümenin gelir eşitsizliği esnekliği orta gelirli ve yüksek gelirli ülkeler için negatif olup Kuznets hipotezi ile de uyumludur. Ancak düşük gelirli ülkeler için sonuçlar yetersiz kalmıştır.

Huang, vd., (2012), Lind ve Mehlum (2010) tarafından geliştirilen yöntem ile ABD için Kuznets hipotezinin geçerliliğini yeniden incelemişlerdir. 1917-2017 dönemini kapsayan analiz sonucuna göre ekonomik büyüme ile gelir eşitsizliği arasındaki ters- $U$ şeklinde kesin bir ilişkinin olduğu varsayımı reddedilmiştir. Jalil (2012), Çin'in 1952-2009 dönemi verilerini kullanarak ARDL modeli ile Kuznets hiptezinin geçerliliğini test etmiştir. Elde edilen bulgular ters-U hipotezini destekler niteliktedir. Kişi başına düşen gelir arttığı zaman ve finansal gelişmenin hızlanmasının gelir eşitsizliğinin azaltıcı etki yaptığı görülmüştür. Huang, vd., (2012) ve Jalil (2012) tarafından yapılan çalışmaların sonuçları benzerdir. Ancak buradaki ayrıt edici nokta çalışmaların Çin ve ABD için yapılmış olmasından kaynaklanmaktadır. İki ülkenin ekonomik ve siyasi sistemlerinin birbirinden çok farklı olduğu düşündüğümüzde elde edilen bulguların benzer olması da düşündürücü olmaktadır.

Shin (2012), gelir eşitsizliği ile ekonomik büyüme arasında olması muhtemel pozitif ya da negatif ilişkiyi aynı anda tek bir model ile ortaya koymuştur. Ekonomik büyümenin ilk aşamalarında gelir eşitsizliği büyüme arasındaki ilişki negatif iken ekonomi durağan durum dengesine ulaştığı zaman bu ilişkinin pozitife döndüğü tespit edilmiştir. Bu durum, yüksek gelir vergisi ile gelirin yeniden dağılımın sağlanmasının daima gelir eşitsizliği üzerinde azaltıcı etki yapmayacak olması ile açıklanmıştır.

Rubin ve Segal (2015), yine ABD için 1953-2008 dönemi verilerini kullanarak Kuznets hipotezini test etmişlerdir. Analiz sonucunda ekonomik büyüme ile gelir eşitsizliği arasındaki ilişkinin üst, orta ve düşük gelir grubundaki bir takım farklılıklara rağmen Kuznets'in ortaya koyduğu şekilde hareket ettiği görülmüştür. Ding, vd., (2015), ekonomik büyümenin gelir eşitsizliği üzerindeki pozitif ya da negatif etkisini Çin için incelemişlerdir. Gini katsayısı ile Lerner endeksinin 1997-2010 döneminin kıyaslanması ile yapılan analiz sonucunda ekonomik büyümenin gelir eşitsizliğini artırdığı tespit edilmiştir. Yapılan bu çalışmaların dönemsel olarak farklılık gösterse bile literatürde daha önce $A B D$ ve Çin için elde edilen bulgularla uyumlu oldukları görülmektedir. 
Ak ve Altıntaş (2016), Türkiye için 1986-2012 dönemini dikkate alarak ARDL sınır testi ile Kuznets hipotezinin geçerliliği araştırmışlar. Kuznets hipotezi Türkiye için ters-U yerine $U$ şeklinde desteklenmiştir. Gelir eşitsizliği ekonomik büyümenin başlangıç aşmalarında gelir eşitsizliği azalırken sonraki süreçte ise eşitsizlik artmıştır. Topuz ve Dağdemir (2016), gelişmiş ve gelişmekte olan 94 ülkenin 1995-2011 dönemine ait verilerini kullanarak Kuznets hipotezinin geçerliliğini araştırmışlardır. Kurulan modellerden elde edilen bulguların Kuznets'in ortaya koyduğu hipotezi destekler nitelikte olduğu görülmüştür. Akıncı ve Akıncı (2016), ekonomik büyüme, finansal gelişme ve gelir eşitsizliği ilişkisi 1960-2014 dönemi dikkate alınarak Türkiye için incelenmiştir. Yapılan analizler sonucunda Türkiye'de ters-U hipotezinin ilgili dönemde geçerli olduğu belirlenmiştir. Akalin, vd., Kuznets'in ortaya koyduğu ters-U hipotezinin geçerliliğini Türkiye için 1984-2011 yıllarına ait veriler ile test etmişlerdir. Çalışmada hem kuadratik hem de kubik model kullanılarak tahminler yapılmıştır. Kuadratik modelin uzun dönem sonuçlarına göre Türkiye'de ilgili dönemde Kuznets eğrisi hipotezi geçerlidir. Kübik modelin sonuçlarına göre ise Türkiye 1984-2011 yılları arasında ekonomik büyüme ve gelir eşitsizliği arasındaki ilişki ters- $\mathrm{N}$ şeklindedir (Akalin, vd., 2018). Türkiye için yapılan analizlerin bir kısmı Kuznets'in hipotezinin ters-U şeklinde geçerli olduğu ortaya koyarken Tokatlıoğlu ve Atan (2007), Ak ve Altıntaş (2016) ve Akalin, vd., (2018) bu ilişkinin tam olarak ters-U şeklinde olmadığı belirtmişlerdir. Ekonomik büyüme ile gelir eşitsizliği arasında ilişkinin olduğunu ancak bunun ters- $N$ ya da sadece $U$ şeklinde olduğu tespit etmişlerdir.

Literatürde farklı ülkeler için farklı dönemleri kapsayan bir çok ampirik çalışma yer almaktadır. Bu çalışmaların temel amacı Kuznets'in ters-U hipotezinin geçerliliğini sorgulamak olmuştur. Elde edilen bulgular bazı ülkeler için Kuznets varsayımının geçerli olduğu ortaya koymuşken bazı ülkeler için ise geçerli olmadığı tespit edilmiştir. Bu çalışmada aynı varsayım doğrultusunda geçiş ülkelerinde ters- $U$ hipotezi analiz edilmiştir. Çalışmanın dayandığı temel model Kuznets'in ters-U hipotezidir ve bu çerçevede panel veri analizi yapılmıştır. Gelişmiş veya gelişmekte olan birçok ülke için ters-U hipotezi sorgulanmıştır ancak çalışmada ele alınan dönem ve ülke grubu için herhangi bir çalışma bulunmamaktadır. Çalışma için seçilen geçiş ülkeleri için Kuznets hipotezi ve ilgili dönem için herhangi bir analizin daha önce yapılmamış olması çalışmanın literatüre olan katkısını ve özgün yanını ortaya koymaktadır.

\section{Kuramsal Çerçeve ve Model}

\subsection{Kuramsal Çerçeve}

Gelirin akım bir değişken olması zamana bağlı olarak belirli bir zaman kısıtı içinde ölçülebildiğini göstergesidir. Gelir bireylerin sahip oldukları bir takım varlıklar yoluyla elde edilmektedir (Rycroft, 2014). Basit bir şekilde harcanabilir gelir, haneye gelen toplam gelirden vergilerin çıkarılması ile elde edilmektedir. Hanede elde edilen türü çoğunlukla ücret ya da maaştan oluşurken iken devlete ödenen vergiler ile sosyal güvenlik ödemeleri de çıkarılan ödemelerdir (Brian, 2015). Toplumda meydana getirilen milli hasılanın bireyler için eşit dağılması durumunda ekonomik ve sosyal yaşam aksamadan devam edecektir. Ancak gelirin onun meydana getirilmesi aşamasında yer alan gruplar arasında hatta aynı grupta yer alan kimseler için dâhi eşit dağılmıyor olması gelir eşitsizliğinin göstergesidir. Gelir eşitsizliği sadece salt gelirin dağılması gibi görünse de ilerleyen süreçlerde ekonomik ve sosyal yönden çok daha karmaşık bir kavram niteliğini almaktadır.

Eşitsizlik ve boyutları ile ilgili tartışmalar oldukça fazladır. Ancak eştisizliği parasal olan ve olmayana olarak basit bir şekilde ayırmak mümkündür. Parasal eşitsizlik hanehalkı ya da bireyin gelir, servet gibi değişkenlerine bağlıdır. Buna karşın parasal olmayan eşitsizlik ise gelir yanında 
daha çok refah seviyesi ile ilgili olup çok boyutlu bir kavramdır(Atkinson ve Bourguignon, 2014). Gelir eşitsizliği ile ilgili ölçütler temelde objektif ve subjektif olmak üzere iki kategoriye ayrımlaktadırlar (Sen, 1997: 2, 24). Bu temel ayrımı da içerek şekilde gelir eşitsizliği Gini Katsayısı, Theil Eşitsizlik Endeksi, Kuznet's Eğrisi (katsayısı), Atkinson Eşitsizlik Ölçütü gibi farklı yöntemlerle tespit edilebilmektedir. Bu farklı ölçütlerden olan ve ekonomik büyüme ile gelir eşitsizliği arasındaki ilişkiyi sorgulayan Kuznet's Ters U Hipotezi çalışmamızın temel teorik arka planını oluşturmaktadır.

Kuznets kullanılabilir gelirin uzun dönemde artmasının mutlak gelir hipotezinde varsayıldığı gibi bireylerin ortalama tüketimini azaltmadığını ortaya koymuştur. Aksine artan gelirin uzun dönemde bireylerin ortalama tüketim eğilimi üzerinde herhangi bir değişikliğe yol açmadığı görülmüştür (Kuznets,1946).

Zaman içerisinde günümüze kadar üzerine oldukça araştırma yapılan ekonomik büyüme ile gelir eşitsizliği ilişkisini ilk defa Simon Kuznets ele almıştır. Uzun dönemde kişisel gelir dağılımındaki değişiklilerin nedenlerini ve karakteristiğini tespit etmek amacıyla yola çıkmıştır. Herhangi bir ülkede gerçekleşen ekonomik büyüme ile birlikte gelir eşitsizliği artıyor mu yoksa azalıyor mu soruları üzerine yoğunlaşmıştır. Kuznets kısıtlı bir veriyle de olsa ABD, Almanya ve İngiltere'deki ekonomik büyüme gelir eşitsizliği ilişkisini analiz etmiştir. Gelirin göreli olarak dağıımı nüfusun büyük bir kısmı için eşitlik yönünde hareket etmekte olup özellikle bu durum 1920'li yıllarda daha belirgindir. Kuznets bu durumun belki birinci dünya savaşı öncesi dönemin bir sonucu olarak görülebileceğini belirtmektedir. Analizini ilerleyen süreçte tarım toplumundan sanayi toplumuna geçişi de dikkate alarak sürdürmüştür. Burada tarım sektöründen tarım dışı sektörlere değişimin gelir eşitsizliğini üzerinde nasıl bir etki yapacağı sorusu ile araştırmasına devam etmiştir. Kuznets çalışmasının ilerleyen süreçlerinde milli gelirden kişi başına düşen pay ile gelir eşitsizliği arasındaki ilişkinin belirli bir noktadan sonra tersine döndügüunü tespit etmiştir. Elde edilen bulgulara göre ekonomik büyümenin başlangıç dönemlerinde gelir eşitsizliği artmakta iken daha sonraki dönemlerde ise gelir eşitsizliği azalmaktadır. Buradan hareketle ekonomik büyüme ile eşitsizlik arasındaki ilişkinin ters-U şeklinde olduğu görülmektedir (Kuznets, 1955). Kuznets dönemin gelişmiş ülke ekonomilerini dikkate alarak ekonomik büyüme ile gelir dağılımı ilişkisini incelemiştir. Ülke ekonomilerinin gelişme aşamalarındaki gelir dağılımı ile ekonomik büyüme arasındaki değişimi ve kişisel gelirdeki değişimi inceleyen Kuznets eğrisi ters-U hipotezi olarak da bilinmektedir (Sarigiannidou ve Palivos, 2012).

\subsection{Yöntem ve Model}

Zaman serilerinin kullanımının bazı sorunlara yol açtığı ve veri zaman boyutu kısıtı nedeniyle yöntemin sorunlu olduğu tartışmaları yapılmıştır. Bunun sonucunda son dönemdeki çalışmalar zaman boyutu kısa ancak oldukça geniş veri kümelerinin analizine yönelmiştir. Analiz teknikleri kesitsel çeşitlilik ve heteroejenlik ile birlikte panel veri analizinin üzerine yoğunlaşmıştır. Panel veri analizinin yatay kesit ve verilerine göre en temel avantajı araştırmacılara bireyler arasındaki davranış farklılıklarının modellenmesi konusunda büyük bir esneklik sağlamasıdır (Greene, 2003).

Panel veri analizinin kullanımı hem yatay kesit hem de zaman boyutunu dikkate almasından dolayı gittikçe daha fazla tercih edilir bir hale gelmiştir. Gözlem sayısı artışı ile çoklu doğrusal bağlantı problemi aşılmış ve daha fazla serbestlik derecesine ulaşılmış olmaktadır. Panel veri setinin kullanımı gelişmekte olan ülkelerde gittikçe yaygınlaşmaktadır. Bu ülkelerin uzun dönemli istatistik toplama geçmişleri olmamasına rağmen panel veri setleri birçok önemli sorunun cevaplanmasında son derece faydalı olmaktadır (Hsiao, 2014). 
Ekonometrik analizlerde kullanılan veriler; zaman serisi, yatay kesit verileri ve hem zaman serisini hem de yatay kesit verisini bir arada sunan havuzlanmış panel verilerinden oluşmaktadır (Gujarati, 2004). Zaman serilerinin yatay kesitlerin her biri için eşit uzunlukta veri mevcut olması durumunda dengeli panel söz konusu iken her bir yatay kesit için uzunluk farkının olması durumu da dengesiz panel olarak tanımlanır (Wooldridge, 2003).

Tüm bu bilgiler doğrultusunda çalışmada yöntem olarak statik panel veri analizi tercih edilmiştir. Model ise Kuznets'in ters-U hipotezini dikkate alarak aşağıdaki gibi kurulmuştur:

$\mathrm{GINI}=\beta 0+\beta 1(\mathrm{GSYiH})$ it $+\beta 2$ (DT)it $+\beta 3(\mathrm{GSYiH} 2)$ it $+\beta 4(\mathrm{KH})$ it $+\beta 5(\mathrm{KSH})$ it $+\beta 6$ (SS)it $+\beta 7$ (TS)it $+\beta 8(\mathrm{EGT})$ it $+u$ it

$\mathrm{i}=1, \ldots .10$ (Geçiş Ekonomileri)

$$
t=1, \ldots 19(1995-2013)
$$

Çalışmada yer alan ülkelerin 1995-2013 yılları arasındaki verileri Dünya Bankası, SWIID (The Standardized World Income Inequality Database) ve UNI-WIDER'den (United Nations Univesity) temin edilerek kullanılmıştır. Araştırılan döneme ait verileri temin edilebilen geçiş ekonomisi ülkeleri sayısı ile sınırlandırma yapılmıştır. Ayrıca ilgili ülke verilerinin güncel olarak ulaşılabilen tarihine kadar dönem sınırlaması yapılmıştır.3

Tablo 1: Çalışmada Kullanılan Değişkenler

\begin{tabular}{lll}
\hline Türü & Kodu & Açıklaması \\
\hline Bağımlı Değişken & GINI & Ülkelerin Gini Katsayıları \\
\hline Bağımsız Değişkenler & GSYiH & 2011 yılı fiyatları ile Kişi Başı GSYiH \\
& DT & Dış Ticaretin GSYiH'ye oranı \\
& GSYiH2 ${ }^{4}$ & 2011 yılı fiyatları ile Kişi Başı GSYï'nin Karesi \\
& KH & 2010 yılı fiyatları ile genel kamu harcamaları \\
& KSH & 2011 Yılı Fiyatları Ile Kişi Başı Sağı̆ı Harcaması \\
& SS & Sabit Sermayenin GSYiH'ye oranı \\
& TS & Tasarrufların GSYiH'ye oranı \\
& EGT & Net Eğitime Katılım Oranı \\
\hline
\end{tabular}

Klasik doğrusal regresyon analizinin katı olan varsayımlarının esnetilebilmesi için panel veri analizi kapsamında sabit etkiler ve rassal etkiler modelleri kullanılmaktadır. Hangi modelin tercih edileceğine Hausman Testi yardımıyla karar verilir. Hausman Testi sabit etkili ve rassal etkili modellerin katsayılarındaki farklııkları analiz ederek araştırmacıya yardımcı olmaktadır (Ahn ve Moon, 2001; Hsiao, 2014). Panel analiz yöntemini tercih eden araştırmacıların veriler üzerinde zaman etkilerinin olmadığı varsayımı ile hareket etmeleri halinde havuzlanmış panel regresyon modelini tercih ettiği bilinmektedir. Eğer araştırmacılar veriler üzerinde birim veya zaman etkilerinin olduğu varsayımından hareket ederlerse sabit etkili ve rassal etkili modelleri tercih edeceklerdir (Gujarati, 2004).

Hausman testi sonuçlarına göre model için sabit etkiler yönteminden elde edilen sonuçlar ile rassal etkiler yönteminden elde edilen sonuçlar arasında istatistiksel açıdan sistematik bir farklııı bulunmaktadır. Bu durumda tahmin sürecinde tüm modeller için sabit etkiler modeli tutarlıdır (Tablo-2).

\footnotetext{
${ }^{3}$ Bulgaristan, Çek Cumhuriyeti, Estonya, Macaristan, Letonya, Litvanya, Polonya, Romanya, Slovak Cumhuriyeti, Slovenya.

${ }^{4}$ Model ve literatür çerçevesinde ülkelerin gelişme sürecindeki ikinci dönemi yansıtması için GSYiH'nin karesi alınarak model kurulmaktadır.
} 
Kurulan modellerde değişen varyans sorunun olup olmadığının tespiti için Wald Testi uygulanmaktadır. Eğer test sonucunda değişen varyans sorunu tespit edilirse modelin dirençli standart hatalar (Robust) yöntemi ile tahmin edilmesi gerekmektedir (Hayes ve Cai, 2007; Stock ve Watson, 2008). Wald testi sonuçları aşağıdaki tablo-2'de verilmiştir. Test sonucuna göre modelde değişen varyans problemi bulunmaktadır. Bu nedenle modelde değişen varyansın çözümü için dirençli hataları içeren robust regresyon kullanılmıştır.

Kurulan modellerin otokorelasyon sorununa sahip olup olmadığını test etmek için literatürde de sıklıkla tercih edilen ve doğru sonuçlar veren GDW (Durbin-Watson Testi Bhargava, Franzini ve Narendranathan 1982) Testi ve LBI- Testi (Baltagi ve Wu,1999) kullanılmaktadır. Yapılan sınama testleri sonıucunda modellerin hem değişen varyansa hem de otokorelasyon içermesi durumunda ise kümelenmil standart hatalar (cluster) yöntemi ile tahmin yapılmaktadır (Wooldridge 2003, Williams 2000, Rogers 1993).

Tablo 2: Wald chi2 ve Hausman Testi

\begin{tabular}{|c|c|c|c|}
\hline \multicolumn{2}{|c|}{ Wald chi2 } & \multicolumn{2}{|l|}{ Hausman } \\
\hline chi2 & Prob>chi2 & $\operatorname{chi} 2(8)=(b-B)^{\prime}\left[\left(V_{-}{ }^{b}-V_{-} B\right)^{\wedge}(-1)\right](b-B)=$ & 150.94 \\
\hline 631.57 & 0.000 & \multicolumn{2}{|c|}{$\begin{array}{c}\text { Prob }>\text { chi2 }=0.000 \\
\left(V_{-} b-V_{-} B \text { is not positive definite }\right)\end{array}$} \\
\hline
\end{tabular}

Ho: sigma(i)^2 = sigma^2 for all $\mathrm{i}$

Test: Ho: difference in coefficients not systematic

Tablo-3'te yer alan Durbin-Watson ve Baltagi-Wu testleri sonuçlarına göre modelimizde otokorelasyon problem saptanmıştır. Bu problemin giderilmesini sağlayan kümelenmiş standart hatalar (cluster) yöntemi ile model yeniden tahmin edilmiştir.

Tablo 3: Durbin-Watson ve Baltagi-WuTest

\begin{tabular}{ll}
\hline Durbin-Watson & Baltagi-Wu(LBI) \\
0.399 & 0.653 \\
Basic threshold value "2" & \\
\hline
\end{tabular}

Yatay kesit verilerinin hata terimleri arasında birimlerarası korelasyon olup olmadığını Pesaran, Friedman ve Frees testlerini kullanarak tespit edebiliriz (Hoyos ve Sarafidis, 2006). Eğer birimlerarası otokorelasyon ve değişen varyans gibi problemlerin varlığı durumunda doğru sonuçlar elde etmek için Driscoll-Kraay (1998) yöntemi kullanılır (Driscoll ve Kraay: 1995, Driscoll ve Kraay: 1998).

Birimler arası korelasyonun tespiti için yapılan Pesaran CD, Friedman ve Frees testleri modelimizde hata terimleri arasında korelasyon olduğunu göstermektedir. Bu sorunun giderilmesi için model Driscoll-Kraay yöntemi ile yeniden tahmin edilmiştir.

Tablo 4: Pesaran CD, Friedman ve Frees Tests

\begin{tabular}{rlr}
\hline & & Friedman Test \\
Pesaran CD Test & $8.553, \operatorname{Pr}=0.4814$ & 1.042 \\
0.639, $\operatorname{Pr}=0.5230$ & & \\
\hline Critical values from Frees' Q distribution & \\
alpha $=0.10: 0.3169$ & \\
alpha $=0.05: 0.4325$ & \\
alpha $=0.01: 0.6605$ & \\
\hline
\end{tabular}




\section{Bulgular}

Dirençli hataları içeren robust regresyon, kümelenmiş standart hatalar (cluster) ve DriscollKraay yöntemi ile 3 farklı şekilde tahmin edilen modelimiz tablo-5'te verilmiştir.

Tablo 5: Model Tahmin Sonuçları

\begin{tabular}{|c|c|c|c|}
\hline & (1) Robust & (2) Cluster & (3)DK \\
\hline Değişkenler & Model-1 & Model-2 & Model-3 \\
\hline \multirow[t]{2}{*}{ In_GSYIH } & $5.096 * *$ & $5.096 * *$ & $5.096 * * *$ \\
\hline & [1.691] & [1.691] & [1.179] \\
\hline \multirow[t]{2}{*}{ In_DT } & -0.016 & -0.016 & -0.016 \\
\hline & [0.067] & [0.067] & [0.068] \\
\hline \multirow[t]{2}{*}{ In_GSYIH2 } & $-0.254 * *$ & $-0.254^{* *}$ & $-0.254 * * *$ \\
\hline & [0.085] & [0.085] & [0.059] \\
\hline \multirow[t]{2}{*}{ In_KH } & 0.004 & 0.004 & 0.004 \\
\hline & [0.103] & [0.103] & [0.041] \\
\hline \multirow[t]{2}{*}{ In_KSH } & -0.057 & -0.057 & $-0.057 *$ \\
\hline & [0.042] & {$[0.042]$} & {$[0.030]$} \\
\hline \multirow[t]{2}{*}{ In_SS } & -0.044 & -0.044 & $-0.044 *$ \\
\hline & {$[0.034]$} & {$[0.034]$} & [0.025] \\
\hline \multirow[t]{2}{*}{ In_TS } & -0.010 & -0.010 & -0.010 \\
\hline & [0.038] & [0.038] & [0.021] \\
\hline \multirow[t]{2}{*}{ In_EGT } & $-0.217 * *$ & $-0.217 * *$ & $-0.217 * *$ \\
\hline & [0.188] & [0.188] & [0.086] \\
\hline \multirow[t]{2}{*}{ Constant } & $-22.562 * *$ & $-22.562 * *$ & $-22.562 * * *$ \\
\hline & [8.800] & [8.800] & [5.682] \\
\hline Observations & 156 & 156 & 156 \\
\hline $\mathrm{F}$ & $(8,9) 7.738$ & $(8,9) 7.738$ & $(8,16) 88.45$ \\
\hline Prob $>\mathrm{F}$ & 0,003 & 0,003 & 0,000 \\
\hline R-squared & 0.484 & 0.484 & \\
\hline Number of countrycode & 10 & 10 & \\
\hline rho & 0.912 & 0.912 & \\
\hline sigma & 0.138 & 0.138 & \\
\hline sigma_e & 0.0408 & 0.0408 & \\
\hline sigma_u & 0.131 & 0.131 & \\
\hline r2_within & 0.484 & 0.484 & 0.484 \\
\hline r2_between & 0.0903 & 0.0903 & \\
\hline r2_overall & 0.101 & 0.101 & \\
\hline Corr & -0.0257 & -0.0257 & \\
\hline Maks.lag & & & 2 \\
\hline
\end{tabular}


Modelimizin her üç yöntem ile tahmin sonuçlarına bakıldığı zaman çok büyük bir farklılığın olmadığı görülmektedir. Dolayısıyla her bir yöntem ile yapılan tahmin tutarlı ve istatistiki olarak anlamlıdır.

Analiz sonuçlarına göre, In_GSYIH ve In_GSYHi2 değişkenlerinin her üç modelde de \%1 ve \%5 düzeyinde istatistiki olarak anlamlı olduğu görülmektedir. Modelde yer alan In_GSYiH değişkenin istatistiki olarak anlamlı olması geçiş ekonomilerinde ekonomik büyüme ile gelir eşitsizliğinin birlikte arttığını göstermektedir. Gelişme sürecinin ikinci aşamasını temsil eden ve GSYiH'nin karesi olan In_GSYHi2 değişkeninin istatistiki olarak anlamlı fakat katsayı işaretinin negatif olması ise ekonomik büyüme ile gelir eşitsizliğinin arasında negatif yönlü bir ilişkinin göstergesidir. Bu sonuçlara baktığımızda geçiş ekonomilerinde Kuznets'in ters-U hipotezine uygun olarak gelişmenin ilk aşamalarında gelir eşitsizliğinin arttığı tespit edilmiştir. Ancak gelişmenin sonraki aşmalarında ise ekonomik büyümenin gelir eşitsizliğini azaltıcı bir etkiye sahip olduğu tespit edilmiştir. Eğitime katılım oranını temsil eden In_EGT değişkenin de istatiksel olarak anlamlı olduğu görülmektedir. Kamu sağlık harcamaları değişkeninin istatistiksel olarak anlamlı olmadığı ancak gelir eşitsizliği üzerinden azaltıcı bir etki yaptığı görülmektedir. Benzer şekilde tasarruf oranı ve sabit sermaye oranı değişkenlerinin katsayı işaretleri her ne kadar istatistiki olarak anlamlı olmasa da gelir eşitsizliği üzerinde azaltıcı etkileri olduğu görülmektedir.

\section{Sonuç}

Bu çalışmada Kuznets'in ters-U hipotezinin geçerliliği geçiş ekonomileri için incelenmiştir. Geçiş ekonomileri olarak adlandırılan ülke grubu içerisindeki verilerine ulaşabilen on ülke incelenmiştir. Çalışmanın temel amacı ülkelerin ekonomik büyüme süreçlerinde gelir dağılımının ne yönde etkilendiğini tespit etmek olmuştur. Gelir dağılımının temel göstergesi olan Gini katsayısı bağımlı değişken olarak modele dâhil edilmiştir.

Literatürdeki çalışmalara baktığımız zaman da ülkelerin bir kısmının ekonomik büyüme süreçleri ile gelir eşitsizliği arasındaki ilişki Kuznets'in ön gördüğü gibi önce artan daha sonar azalan bir seyir halindedir. Yine bazı ülkeler için de Kuznets'in ön görüsünün tam aksi yönde bulgular elde eidlmiştir. Bu iki sonucun yanı sıra bazı ülkeler için elde edilen farklı bir sonuç ise ekonomik büyüme ile gelir eşitsizliği arasındaki ilişki Kuznets'in ön gördüğü gibi ters-U şeklinde olmayıp sadece $U$ şeklinde olduğudur. Geçiş ülkeleri için yapılan bu çalışmanın soncunda elde edilen bulgular Kuznets'in ters-U hipotezini desteklemektedir. Dolayısıyla çalışma literatürde yer alan ve çoğunlukla elde edilen bulgular ile tutarlı bir sonuca sahiptir. Daha öncede belirtildiği çalışmanın literatürden farklı olan yönü çalışmaya dâhil edilen geçiş ülkeleri ile ilgili Kuznet's hipotezi kapsamında herhangi bir analizin yapılmamış olmasıdır.

Çalışmada yer alan kontrol değişkenlerinden eğitime katılım oranın gelir eşitsizliği üzerindeki etkisi istatiksel olarak anlamlı olduğu da görülmektedir. Bu durum eğitim seviyesi artışı ile gelir eşitsizliğinin ve yoksulluğun azaldığını göstermektedir. Ayrıca her ne kadar istatiksel olarak anlamlı olmasa da kamu sağlık harcamaları gibi değişkenlerin gelir eşitsizliği üzerinde azaltıcı bir etki yaptığı görülmektedir.

Gelir eşitsizliği ülke içerisindeki gelirin ya da hâsılanın adil olarak paylaşılmamasının bir sonucudur. Meydana getirilen milli hâsılanın eşit paylaşımı ile birlikte adil olarak paylaşımını da önemli bir belirleyicidir. Gelir dağılımındaki dengesizliğin sonucu doğrudan yoksulluk olgusunu ortaya koyan en önemli faktördür. Yoksullukla mücadele birçok yaklaşım ve yöntem kullanılmakta olup bunlardan bir tanesi de ekonomik büyüme ile yoksulluğu azaltma çabalarıdır. Bu 
mücadelenin bir sonucu da elbette gelir eşitsizliğinin artması ya da azalması olmaktadır. Ülkelerin kendilerine ait ekonomik ve sosyal farklılıkları da gelir eşitsizliği ve ekonomik büyüme ilişkisinin yönüne etki etmektedir. Gelişmiş ve gelişmekte olan ülkeler için yapılan ampirik çalışmaların bir kısmında Kuznets hipotezinin farklı şekilde sonuç vermesi bunun göstergesidir.

Ekonomik büyümenin sadece milli gelirin rakamsal bir artışını yansıttığı da unutulmamalıdır. Önemli olanın büyüme ile birlikte sosyal ve ekonomik kalkınmanın sağlanabilmesidir. Ekonomik büyüme yoluyla yoksullukla mücadele dolaylı bir yaklaşım olup etkileri belirli bir dönem sonra tespit edilebilir. Kuznets hipotezi de benzer şekilde gelişim dönemlerini ülkeler için ikiye ayırmaktadır. Bu şekilde gelir dağılımında meydana gelecek bir bozulma ya da düzelmenin tespiti kolaylıkla yapılabilir. Ancak bazı durumlarda gelir eşitsizliğine ve yoksulluğa müdahale için zamanlamanın öne çekilmesi gerekmektedir. İşte böyle bir durumda ise doğrudan mücadele politikaları ve sosyal devlet çözüme götüren kavramlar olarak görülmektedir. Gelir eşitsizliğinin varlığı sadece kendi başına bir sorun olmayıp sosyal ve ekonomik birçok alan üzerinde de etkilidir. Gelir dağılımında adaletin sağlanması ile eş zamanlı olarak birçok sosyal ve ekonomik probleminde kendi içerisinde çözüme yöneleceği unutulmamalıdır. Tasarruf oranlarının artışı özellikle yoksul kesim için önemli bir durumun göstergesidir. Çünkü birey asgarinin üzerinde bir gelire sahip ise tasarrufa yönelecektir. Eğer bireyler ancak geçimlik düzeyde bir gelire sahipler ise tasarruftan söz etmek mümkün değildir. Kamu sağlık harcamalarının artışı ise bireylerin fiziki olarak işgücü piyasasına ve sosyal yaşama daha fazla dâhil olmalarına katkı sunacaktır. Sağlıksız bir kimsenin üretime katılması ve gelir elde etmesi mümkün olmadığı gibi sosyal yaşamda da dilediği gibi yer alamayacaktır. Gelir eşitsizliğinin azaltılması için eğitime katılımda, sağıı olanaklarına erişim ve kamu harcamalarından faydalanmada eşitlik sağlanmalıdır. 


\section{Eskişehir Osmangazi Üniversitesi iiBF Dergisi}

\section{Kaynaklar}

Ahn, C. Seung ve Moon, R. Hyungsik. (2001). Large-N And Large-T properties of panel data estimators and the Hausman test. USC Center for law, economics \& Organization, Research Paper No: C01-20.

Ak, Mehmet Z. ve Altıntaş, Nurullah (2016), “Kuznets'in ters U eğrisi bağlamında Türkiye'de gelir eşitsizliği ve ekonomik büyüme ilişkisi: 1986-2012", Maliye Araştırmaları Dergisi, 2(3), 93-102.

Akalin, Güray; Özbek, Rabia İ. ve Çiftçi, İsmail (2018), "Türkiye’de gelir dağılımı ve ekonomik büyüme arasındaki ilişki: ARDL sınır testi yaklaşımı", Journal of Kastamonu University FEAS, 20/4, 59, 76, 2.

Akıncı, Gönül Y. ve Akıncı, Merter (2016), "Ters-U Hipotezi Bağlamında Ekonomik Büyüme, Finansal Kalkınma ve Gelir Eşitsizliği Mekanizmaları Üzerine", Finans Politik ve Ekonomik Yorumlar, 53(622), 61.

Anand, Sudhir ve Kanbur, SM Ravi (1993a), Inequality and development a critique", Journal of Development economics, 41(1), 19-43.

Anand, Sudhir ve Kanbur, SM Ravi (1993b), "The Kuznets process and the inequality-development relationship", Journal of development economics, 40(1), 25-52.

Atkinson, Anthony B ve Bourguignon, François (Eds.) (2014), Handbook of income distribution, (Vol. 2), Elsevier.

Barro, Robert, J. (2000), "Inequality and Growth in a Panel of Countries", Journal of economic growth, 5(1), 5-32.

Brian, Keeley (2015), OECD Insights Income Inequality the Gap between Rich and Poor: The Gap between Rich and Poor, OECD Publishing.

Chen, Been, L. (2003), “An inverted-U relationship between inequality and long-run growth”, Economics Letters, 78(2), 205-212.

Dawson, P. (1997), “On testing Kuznets' economic growth hypothesis”, Applied Economic Letter, Vol. 4 No. 7, 409-10.

Desbordes, Rodolphe ve Verardi, Vincenzo (2012). "Refitting the Kuznets curve”, Economics Letters, 116(2), 258-261.

Deutsch, Joseph ve Silber, Jacques (2004), "Measuring the impact of various income sources on the link between inequality and development: Implications for the Kuznets curve", Review of Development Economics, 8(1), 110-127.

Ding Xun; Dong Tian; Xu Yanjie ve Zheng Zheng (2015), "Does economic growth positively affect income inequality in China?", Deakin Papers on International Business Economics, 8(1).

Dişbudak, Cem ve Süslü, Bora (2007), "Türkiye'de kişisel gelir dağılımını belirleyen makroekonomik faktörler”, Ekonomik Yaklaşım, 18(65), 1-23.

Driscoll, John ve Kraay, Aart (1995), Spatial Correlations in Panel Data, Te World Bank Policy Research Department, Policy Research Working Paper, No: 1553.

Driscoll, John ve Kraay, Aart (1998), “Consistent Covariance Matrix Estimation with Spatially Dependent Data”, Review of Economics and Statistics, 80, 549-560.

Gallet, Craig A. ve Gallet, Rachel M. (2004), "US growth and income inequality: evidence of racial differences", The Social Science Journal, 41(1), 43-51.

Greene, William H. (2003), Econometric analysis,Pearson Education India.

Gujarati, Damodar N. (2004), Basic Econometrics, (4 th edtn) The McGraw- Hill Companies.

Hayes, Andrew F. ve Li, Cai (2007), Using HeteroskedasticityConsistent Standard Error Estimators in OLS Regression: An Introduction and Sofware Implementation, Behavior Research Methods, 39 (4), 709-722.

Hoyos, Rafael E. ve Sarafidis, Vasilis (2006), "Testing for CrossSectional Dependence in Panel Data Models" The Stata Journal, 6 (4), 482-496.

Hsiao, Cheng (2014), Analysis of panel data, No. 54, Cambridge University press.

Huang, Ho-Chuan R. (2004), "A flexible nonlinear inference to the Kuznets hypothesis", Economics Letters, 84(2), 289296.

Huang, Ho- Chuan; Lin, Yi-Chen ve Yeh, Chih-Chuan (2012), "An appropriate test of the Kuznets hypothesis", Applied Economics Letters, 19(1), 47-51.

Jalil, Abdul (2012), “Modeling income inequality and openness in the framework of Kuznets curve: New evidence from China", Economic Modelling, 29(2), 309-315.

Khasru, Syed, M. ve Jalil, Mohammad, M. (2004), “Revisiting Kuznets hypothesis: An analysis with time series and panel data", The Bangladesh Development Studies, 89-112.

Kuştepeli, Yeşim (2006), “Income inequality, growth, and the enlargement of the European Union”, Emerging Markets Finance and Trade, 42(6), 77-88. 
Kuznets, Simon, (1946), National Product Since 1869, National Bureau Of Economic Research, Newyork.

Kuznets, Simon, (1955), "Economic Growth and Income Inequality”, The American Economic Review, 1-28.

List, John A. ve Gallet, Craig, A. (1999), "The Kuznets Curve: What Happens After the Inverted-U?”, Review of development economics, 3(2), 200-206.

Malinen, Tuomas (2012), "Estimating the long-run relationship between income inequality and economic development", Empirical Economics, 42(1), 209-233.

Laszlo, Matyas; Laszlo, Konya ve Macquarie, Lachlan (1998), "The Kuznets U-curve hypothesis: some panel data evidence", Applied Economics Letters, 5(11), 693-697.

Mollick, André V. (2012), "Income inequality in the US: The Kuznets hypothesis revisited", Economic Systems, 36(1), 127-144.

Muinelo-Gallo, L. ve Roca-Sagalés, O. (2011), "Economic growth and inequality: the role of fiscal policies", Australian Economic Papers, 50(2-3), 74-97.

Nel, Philip. (2003), "Income inequality, economic growth, and political instability in sub-Saharan Africa", The Journal of Modern African Studies, 41(4), 611-639.

Ongan, T. Hakan (2004), “Gelir eşitsizliği, doğrudan yabancı sermaye yatırımları ve ters u eğrisi”, İstanbul Üniversitesi iktisat Fakültesi Mecmuası, 54(1), 153.

Paukert, Felix (1973), "Income distribution at different levels of development: A survey of evidence", Int'l Lab. Rev., 108, 97.

Ram, Rati (1989), "Level of Development and Income Inequality: An Extension of Kuznets-Hypothesis to the World Economy", Kyklos, 42(1), 73-88.

Ram, Rati (1997), "Level of economic development and income inequality: evidence from the postwar developed world", Southern Economic Journal, Vol. 64, 576-83.

Rehman, Hafeez. U; Khan, Sajawal ve Imtiaz, Ahmed (2008), "Income distribution, growth and financial development: A cross countries analysis", Pakistan Economic and Social Review, 1-16.

Rehme, G. (2007), "Education, economic growth and measured income inequality”, Economica, 74(295), 493-514.

Robinson, Sherman (1976), "A Note on the U Hypothesis Relating Income Inequality and Economic Development", American Economic Review, vol. 66,437-440.

Rogers, William H. (1993), "Regression Standard Errors in Clustered Samples", Stata Technical Bulletin, 13 (3), 19-23.

Rubin, Amir ve Segal, Dan (2015), "The effects of economic growth on income inequality in the US", Journal of Macroeconomics, 45, 258-273.

Rycroft, Robert S. (2014), The Economics of Inequality, Discrimination, Poverty, and Mobility, Routledge.

Sarıgıannıdou, Maria ve Theodore Palivos (2012), “A Modern Theory of Kuznets'Hypothesis” Texas Christian University Department of Economics Department Working Paper Series, (No. 201202).

Sen, Amartya (1997), On Economic Inequality, Oxford University Press Catalogue.

Shahbaz, Muhammad (2010), "Income inequality-economic growth and non-linearity: a case of Pakistan", International Journal of Social Economics, 37(8), 613-636.

Shin, Inyong (2012), "Income inequality and economic growth", Economic Modelling, 29(5), 2049-2057.

Stock, James H. ve Watson, Mark W. (2008), "Heteroskedasticity-robust Standard Errors for Fixed Effects Panel Data Regression", Econometrica, 76 (1), 155-174.

Thornton, John (2001), "The Kuznets inverted-U hypothesis: panel data evidence from 96 countries", Applied Economics Letters, 8(1), 15-16.

Tokatlıoğlu, İbrahim ve Atan, Murat (2007), "Türkiye'de Bölgeler Arası Gelişmişlik Düzeyi Ve Gelir Dağılımı Eşitsizliği: Kuznets Eğrisi Geçerli Mi?”, Ekonomik Yaklaşım, 18(65), 25-58.

Topuz, Seher G. ve Dağdemir, Özcan (2016), “Ekonomik büyüme ve gelir eşitsizliği ilişkisi: Kuznets ters-u hipotezi'nin geçerliliği”, Eskişehir Osmangazi Üniversitesi iiBF Dergisi, 11(13), 115-130.

Williams, Rick L. (2000), "A Note on Robust Variance Estimation For Cluster-Correlated Data”, Biometrics, 56: 645-646.

Wooldridge, Jeffrey M.(2003), "Cluster-sample methods in applied econometrics”, American Economic Review, 93(2), 133-138.

Zang, Hyoungsoo (1998), "The stability of the Kuznets Curve: some further evidence”, Applied Economics Letters, 5(3), 131-133. 


\section{Extended Summary}

\section{The Relationships between Income Inequality and Economic Growth: Panel Data Analysis on Transition Economies}

Income inequality is an extreme disparity of income distributions among individuals in a particular country. Sustainability of income in a country depends on fairness in distribution of income. Injustice in income distribution is the determining factor in poverty. Many approaches and methods are used to fight poverty. One of these methods is efforts to reduce poverty by ensuring economic growth. This method is not always successful, but sometimes this method can lead to increased income inequality. Economic and social differences between countries determine how the income inequality and economic growth relationship will be realized. Empirical studies for developed and developing countries show that the Kuznets hypothesis has different results in income distribution.

Economic growth is different from economic development and reflects a quantitative increase in national income. The important thing is to achieve social and economic development along with economic growth. Using only economic growth in measuring the fight against poverty has some shortcomings. Kuznets hypothesis divides development periods into two parts for countries. In this case, the results of changes in income distribution will be determined more clearly. However, in some cases, rapid intervention should be made for success in income inequality policy. In this case, direct policies and welfare state policies will be effective. The aim of this study to examine the relationships between income inequality and economic growth for transition economies and to test the validity of the Kuznets hypothesis

There are numerous studies that test Kuznets' relationship between income inequality and economic growth. In most of these studies, the Kuznets hypothesis was confirmed. Although there is no consensus on the current studies, new researches on the Kuznets hypothesis are being revealed. The main difference and original aspect of this study from other studies is that such a study as far as we know, has not been done for the transition economies. The validity of the Kuznets hypothesis has been proved by the results of the study for transition economies. Other findings obtained from the study, the transition countries can achieve effective results in combating income inequality and poverty if they increase educational investments.

It is argued that income, which represents the value created as a result of the production processes, has a significant impact on the economies of the country in terms of the income distribution. There are many and varied factors affecting income distribution. In this study, the effects of economic growth on income distribution were analyzed by using static panel data method. Economic growth and Gini data for the years 1995-2013 were used for ten selected transition economies. The main purpose of the study is to test the validity of the Kuznets inverse-U hypothesis.

In this study, the relationship between income inequality and economic growth is analyzed for transition economies. While investigating the relationship between economic growth and income inequality, the problem initially investigated was theoretically grounded and then similar empirical studies in the literature were summarized. The use of time series due to time constraint leads to a number of problems. In the analysis with more than one country, it is necessary to use a method that takes into account both the horizontal cross-section and the time dimension. In some cases where it is difficult to reach the reliable data of developing countries and some developed countries, panel data analysis was preferred as the method of empirical examination for the relevant countries. After the explanation of the theoretical framework, the relationship between economic growth and income inequality was investigated by using panel data analysis according to Kuznets's Inverse-U Hypothesis for ten countries in the transition economies.

The data of the countries included between 1995 and 2013 were obtained from the World Bank, SWIID (The Standardized World Income Inequality Database) and UNI-WIDER (United Nations University). The data is limited for the research period to the number of transition economies countries that can be obtained. In addition, the relevant country data is limited to the current and fully available date.

The study for transition economies is supports Kuznets' inverse $U$ hypothesis. Therefore, the study is consistent with the findings obtained from the literature and most commonly obtained. According to the findings of the study, income inequality increased in the early stages of economic development in transition economies, consistent with the Kuznets inverse-U hypothesis. In the later stages of development, it was determined that economic growth had a declining effect on income inequality.

The effect of educational level, which is one of the control variables, on income inequality is statistically significant and positive. This shows that income inequality and poverty have decreased as a result of the increase in education level. Moreover, the effect of public expenditures on income inequality was not statistically significant. Overall, the results support the Kuznets inverse- $U$ hypothesis in transition economies examined. 